\title{
Safe-Haven Assets, Financial Crises, and Macroeconomic Variables: Evidence from the Last Two Decades (2000-2018)
}

\author{
Marco Tronzano \\ Department of Economics, School of Social Sciences, University of Genoa, Via Vivaldi 5, 16126 Genoa, Italy; \\ m.tronzano@mclink.it or tronzano.marco@gmail.com; Tel.: +39-10-2095226
}

Received: 14 January 2020; Accepted: 23 February 2020; Published: 28 February 2020

\begin{abstract}
This paper focuses on three "safe haven" assets (gold, oil, and the Swiss Franc) and examines the impact of recent financial crises and some macroeconomic variables on their return co-movements during the last two decades. All financial crises produced significant increases in conditional correlations between these asset returns, thus revealing consistent portfolio shifts from more traditional towards safer financial instruments during turbulent periods. The world equity risk premium stands out as the most relevant macroeconomic variable affecting return co-movements, while economic policy uncertainty indicators also exerted significant effects. Overall, this evidence points out that gold, oil, and the Swiss currency played an important role in global investors' portfolio allocation choices, and that these assets preserved their essential "safe haven" properties during the period examined.
\end{abstract}

Keywords: safe-haven assets; gold price; Swiss Franc exchange rate; oil price

JEL Classification: C22; G15

\section{Introduction and Motivation}

A financial asset is referred to as a "safe haven" asset if it provides hedging benefits during periods of market turbulence. In other words, during periods of market stress, "safe haven" assets are supposed to be uncorrelated, or negatively correlated, with large markets slumps experienced by more traditional financial assets (typically stock or bond prices).

The financial literature identifies various asset classes exhibiting "safe haven" features: gold and other precious metals, the exchange rates of some key international currencies against the US dollar, oil and other important agricultural commodities, and US long-term government bonds.

This paper contributes to the existing literature focusing on some of the most representative "safe haven" assets, namely gold, the Swiss Franc/US dollar exchange rate, and oil. The main motivation behind this choice is twofold.

First, empirical research on these assets have attracted major attention in recent years, both from academia and from institutional investors. Second, there are some weaknesses in the applied literature that need to be addressed.

The hedging properties of gold and its monetary role as a store of value are widely documented. Jaffe (1989) and Chua et al. (1990) find that gold yields significant portfolio diversification benefits. Moreover, the "safe haven" properties of gold in volatile market conditions are widely documented: See, among others, Baur and McDermott (2010), Hood and Malik (2013), Reboredo (2013), and Ciner et al. (2013).

The popular views of gold as a store of value and a "safe haven" asset are well described in Baur and McDermott (2010). As reported by these authors, the 17th Century British Mercantilist Sir William 
Petty described gold as "wealth at all times and all places" (Petty 1690). This popular perception of gold spreads over centuries, reinforced by its historic links to money, and even today gold is described as "an attractive each way bet" against risks of financial losses or inflation (Economist 2005, 2009).

Turning to the role of the Swiss Franc as a "safe haven" asset, Ranaldo and Söderlind (2010) documented that the Swiss currency yields substantial hedging benefits against a decrease in US stock prices and an increase in forex volatility. These findings corroborate earlier results (Kugler and Weder 2004; Campbell et al. 2010). More recent research documented that increased risk aversion after the 2008 global financial turmoil strengthened the "safe haven" role of the Swiss currency (Tamakoshi and Hamori 2014).

The oil hedging properties have mostly been underlined in relation to government bonds, since oil price increases are usually related to an increase in expected inflation which, in turn, negatively affects bond prices. Recent research provides strong evidence in this direction, confirming that oil qualifies as a "safe haven" financial instrument against government bonds on most international financial markets (Nguyen and Liu 2017), particularly under distressed market conditions (Ciner et al. 2013).

Although the recent literature made consistent progresses applying various econometric methodologies, there are still some notable shortcomings in existing applied work.

More specifically: (1) The effects of financial crises on time-varying correlations between these assets have rarely been explored, notwithstanding the occurrence of many crises episodes in the latest years; (2) the effects of macroeconomic and financial variables potentially affecting the degree of agents risk-aversion (and hence dynamic correlation patterns) have likewise been seldom addressed.

The former issue is almost completely neglected in recent contributions (e.g., Ding and Vo 2012; Ciner et al. 2013; Creti et al. 2013; Jain and Biswal 2016; Poshakwale and Mandal 2016; Kang et al. 2016, 2017; Nguyen and Liu 2017). Only a small number of papers explore the impact of crises episodes either on dynamic correlations (Tamakoshi and Hamori 2014) or modeling return co-movements through copula theory (Bedoui et al. 2018); these contributions, moreover, focus exclusively on the 2007/2009 global financial crisis.

A similar weakness is apparent with regards to the impact of macroeconomic and financial variables, since the bulk of applied work neglects their potential effects on dynamic correlations. One relevant exception is represented by Poshakwale and Mandal (2016), which documents a significant impact of macroeconomic, non-macroeconomic, and financial variables on "safe haven" assets co-movements.

A better understanding of factors driving time-varying conditional correlations is important both to assess the effective relevance of the hedging properties of "safe haven" assets and from an optimal asset allocation perspective.

Since "safe haven" assets are presumed to offer protection against market slumps, one would expect, during each financial crisis, a massive portfolio shift towards these assets with consequent increases in their return co-movements. As shown in Bedoui et al. (2018), this was actually the case during the 2007/2009 global financial crisis, since the dependence structures among oil, gold, and Swiss Franc returns significantly rose with respect to untroubled periods. However, how robust is this empirical evidence to financial crises occurring after the 2007/2009 turmoil? In other words, do "safe haven" assets consistently display their hedging properties during all financial crises?

Similar questions arise with regards to the influence of economic and financial variables on dynamic correlations. Poshakwale and Mandal (2016) consider three "safe haven" assets (gold, oil, 10-year US government bonds) and document a significant impact of non-macroeconomic variables on their return co-movements. How robust are these results to a change in the bundle of "safe haven" assets? How robust is this empirical evidence to different, and potentially equally relevant, economic and financial variables such as systemic stress indicators, economic policy uncertainty indicators, consumer confidence indicators, or the world equity risk premium? As discussed in Poshakwale and Mandal (2016), the forecasting performance of models explaining asset return co-movements is an important issue in asset allocation problems, and a better knowledge of variables driving correlation patterns is important for international investors and portfolio managers. Asset return co-movements, 
in other words, have an economic value when implementing dynamic asset allocation strategies (Guidolin and Timmermann 2007).

In light of the above discussion, this paper takes a first step towards a more accurate investigation of dynamic linkages among three important "safe haven" assets. Since the analysis does not include any traditional financial asset, the purpose of this paper is not to assess the hedging properties of gold, oil, and the Swiss franc but, more simply, to explore the underlying determinants of their correlation patterns during the last two decades.

The structure of the paper is as follows. Section 2 describes the data set and provides some descriptive statistics. Section 3 implements a standard econometric approach, i.e. the Multivariate Garch Dynamic Conditional Correlation (DCC) model of Engle (2002), in order to obtain time-varying conditional correlations estimates. On this basis, Section 4 explores the determinants of dynamic linkages among gold, oil, and the Swiss Franc, focusing on the impact of recent financial crises and of some relevant economic variables. Section 5 concludes.

\section{Data and Descriptive Statistics}

The analysis relies on monthly data from 1999M1 to 2018M10. All data were obtained from Thomson Reuters/Datastream. ${ }^{1}$ Gold price is expressed in US Dollars (henceforth USD) and refers to one troy ounce gold bullion. Oil price is expressed in USD and refers to the spot price of Brent Crude Oil per barrel. With regards to the Swiss Franc/USD exchange rate, the Swiss Franc is assumed as the domestic currency (number of Swiss Franc units per one USD unit).

Increases in gold and oil prices correspond to increases in these assets returns, whereas the reverse holds for the Swiss currency. A decrease in the exchange rate corresponds to a Swiss Franc appreciation, thus capturing an increase in Swiss Franc returns.

Figures 1-3 plot the evolution of these series.

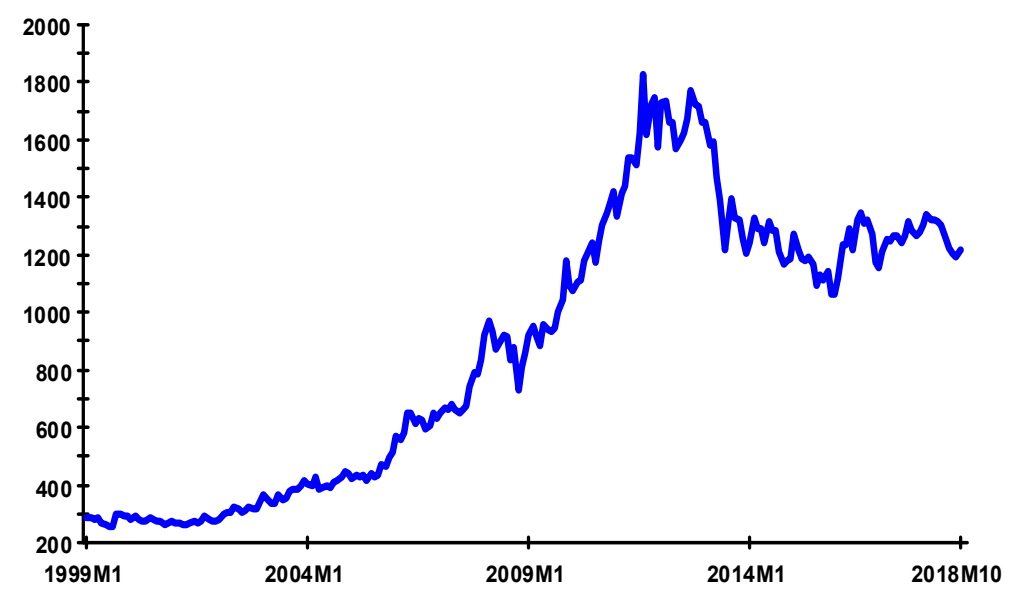

Figure 1. Gold price.

1 The relevant references and Thomson Reuters codes are the following: Gold: Gold Bullion LBM \$/t oz; Thomson Reuters code: GOLDBLN. Oil: Crude Oil-Brent Spot Price; FOB USD/BBL; Thomson Reuters code: EIACRBR. Swiss Franc: Swiss Franc/USD Exchange Rate; End-of-Month Data; Thomson Reuters code: TDCHFSP. 


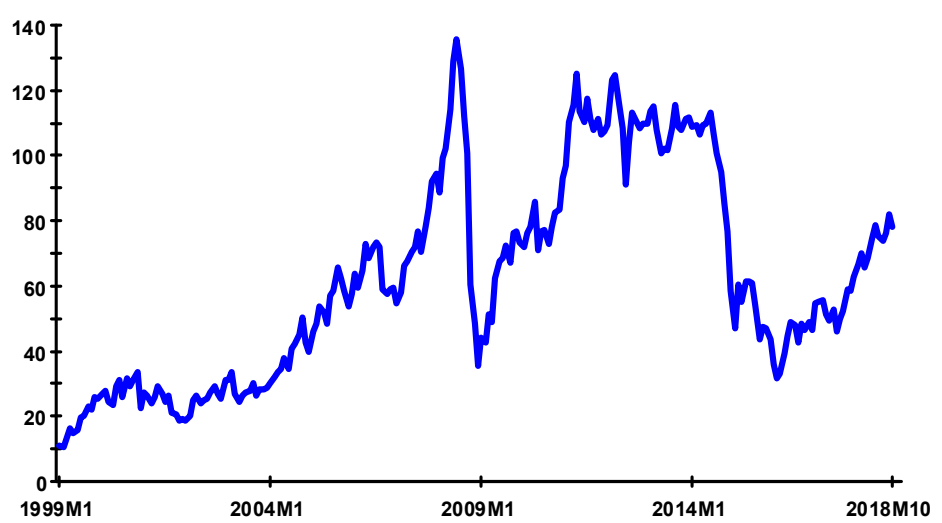

Figure 2. Oil price.

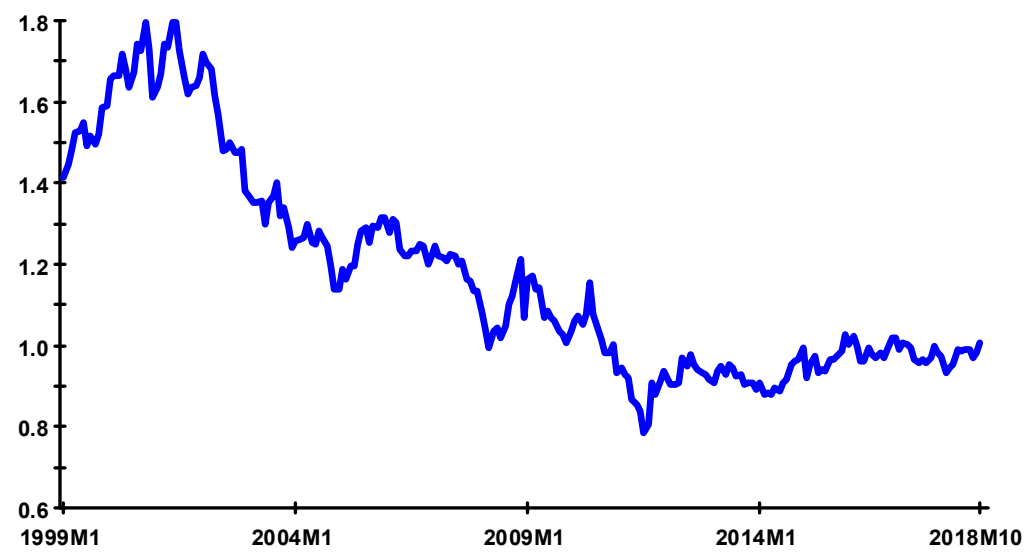

Figure 3. Swiss Franc/USD exchange rate.

The gold price exhibits a strong increasing trend during most of the sample. This trend was suddenly, but only temporarily, interrupted from the second quarter of 2008 to the end of that year. According to the consensus view, although gold market fundamentals remained favorable throughout 2008 , this temporary slowdown was caused by an "investors meltdown" during the global financial crisis, which induced a massive selling of all assets (including gold and silver) by highly leveraged investors in order to cover losses in other markets. From early 2009 to November 2011 (when a record peak was reached), gold price replicated a steady and even faster increasing trend, apparently displaying its "safe haven" property during most of the Eurozone debt crisis. After a prolonged downturn in 2013, usually attributed to concomitant causes (China's weak gold demand, Cyprus Central Bank gold sales, massive ETF's sales, and bearish gold reports by major investment banks), the gold price stabilized in subsequent years oscillating around a stable trading range.

Focusing on the oil price (Figure 2), a similar increasing trend characterized the first part of the sample (1999-2008), with this series reaching an all-time-high in June 2008. The main cause was a persistent excess demand for oil induced by unprecedented growth rates in newly industrialized countries. An impressive decline occurred since the second half of 2008, with the oil price plummeting at historically low values in December 2008. This tendency was again almost entirely demand-driven, given the sharp oil demand contraction associated with the world global recession. A price rebound characterized the 2009-2012 period, with oil price increases mostly conditioned by unexpected recovery growth prospects in the earlier phase, a progressive tightening of oil supply, and other exogenous factors in 2011 (Arab spring, Libyan civil war). After an erratic lateral phase from 2013 to the first half of 2014, a further relevant downswing until end 2015 is apparent, as a consequence of a mix of supply (increased oil production) and demand factors (slower growth in major emerging market economies). A new steady oil price increase characterized the last part of the sample (2016-2018). A series of 
concomitant factors contributed to this process: stronger than expected economic growth, a curb in oil production, geopolitical events, and a persistent decline in inventories due to a precautionary increase in oil demand.

The Swiss Franc exchange rate (Figure 3) exhibited a lower variability. Moreover, differently from gold and oil prices, this series was characterized by two distinct long-run trends.

The former corresponds to a long-run appreciation against the USD, which, albeit with frequent short-run fluctuations, lasted for more than one decade. Starting from a peak value in October 2000, the exchange rate reached an all-time low in July 2011, generating an overall Swiss Franc appreciation of more than $50 \%$. The final phase of this trend roughly corresponded to the global and the Eurozone debt crisis, during which the Swiss currency confirmed its role as a major "safe haven" asset. The massive Swiss Franc appreciation during this last phase forced domestic authorities to implement large expansionary unconventional monetary policy measures in order to counteract widespread deflationary pressures (Jäggi et al. 2019). The latter long-run trend corresponded to the final part of the sample (2012-2018), during which the Swiss Franc fluctuated around a 1:1 parity against the USD. This narrow trading range may be ascribed to the absence of significant shocks on the forex market, and to a temporary exchange rate floor for the Swiss currency introduced from September 2011 to December 2014.

The analysis of the next section relies on monthly returns, computed taking the first differences of the series expressed in natural logs. Standard unit root tests show that the log-levels of these series are not stationary, whereas their log-first differences are stationary. Table 1 contains some descriptive statistics on these asset returns.

Table 1. Descriptive statistics for asset returns.

\begin{tabular}{cccc}
\hline Statistics & Gold & Oil & Swiss Franc \\
\hline Mean & 0.0061 & 0.0082 & -0.0014 \\
Standard Deviation & 0.0479 & 0.1073 & 0.0300 \\
Skewness & -0.1237 & -0.8253 & -0.2147 \\
Excess Kurtosis & 1.043 & 2.635 & 1.820 \\
Jarque-Bera & $11.35^{* * *}$ & $95.49^{* * *}$ & $34.55^{* * *}$ \\
ARCH (1) & $4.36^{* *}$ & $8.63^{* * *}$ & $6.81^{* * *}$ \\
ARCH (2) & $5.48^{*}$ & $16.58^{* * *}$ & $7.28^{* *}$ \\
Ljung-Box (1) & 2.60 & 0.069 & 2.20 \\
Ljung-Box (6) & 5.45 & 2.79 & 7.74 \\
Ljung-Box (12) & 13.52 & 11.02 & 16.79 \\
\hline
\end{tabular}

Jarque-Bera: Jarque and Bera (1980) test for the null hypothesis of normality. ARCH: ARCH test for the null hypothesis of homoscedasticity. Ljung-Box: Ljung-Box portmanteau test for the null hypothesis of absence of serial correlation. ***: Significant at a 1\% level; **: Significant at a 5\% level; *: Significant at a 10\% level.

All mean returns were extremely small and not statistically different from zero. This result is consistent with a large body of empirical evidence according to which financial time series evolve like driftless random walks.

All returns displayed a high variability, as documented by standard deviations that were relatively larger than those usually recorded in the literature (see e.g., (Ciner et al. 2013) for gold and oil, and (Tamakoshi and Hamori 2014) for the Swiss Franc). This suggests that more recent financial crises played a not-negligible role in fostering assets returns variability.

All returns exhibited negative skewness, i.e., they are more likely to be far below than far above the mean, in line with an empirical regularity characterizing financial variables. Moreover, all returns displayed positive excess kurtosis, pointing out heavier tails relative to the normal distribution. This is again a typical feature of financial time series, usually displaying a higher probability of extreme outcomes. In line with the above results, the Jarque and Bera (1980) statistics strongly rejects the null of normality for all returns distributions. 
ARCH tests at lags (1) and (2) always reject the null of homoscedasticity, implying that a multivariate GARCH specification is an appropriate framework to model conditional volatility. Finally, the Ljung-Box test at various lag orders $(1,6,12)$ supported the absence of serial correlation. This result may be ascribed to the monthly frequency used in this paper instead of higher data frequencies usually employed in the literature. The monthly frequency is motivated by one main purpose of the present paper, i.e., the search for potential macroeconomic determinants of time-varying correlations.

Table 2 contains the (static) pair-wise correlations between assets returns.

Table 2. Correlation matrix of asset returns.

\begin{tabular}{cccc}
\hline Assets & Gold & Oil & Swiss Franc \\
\hline Gold & 1.000 & & \\
Oil & 0.157 & 1.000 & \\
Swiss Franc & -0.412 & -0.031 & 1.000 \\
\hline
\end{tabular}

All correlation coefficients were significant at the 5\% level according to the Pesaran and Timmermann (1992) nonparametric test. The highest coefficient amounted to -0.412 , pointing out a positive correlation between gold and Swiss Franc returns (remember that a decrease in the Swiss/USD Dollar exchange rate corresponds to an increase in Swiss Franc returns). The lowest coefficient was -0.031 , pointing out a weak positive association between oil and Swiss Franc returns. Finally, a positive correlation (0.157) between gold and oil returns is shown in Table 2. Overall, therefore, this evidence documents a positive correlation between all assets returns.

The plot of asset returns (not reported in order to save space but available upon request) revealed that the significant ARCH effects documented in Table 1 are, to a large extent, driven by the financial crises of the last two decades. Significant volatility increases characterized the central part of the sample (2008-2011), broadly corresponding to the global financial crisis and to the Eurozone debt crisis.

\section{A Multivariate Garch Model of Asset Returns}

This section employs a well-known approach belonging to the class of Multivariate Garch estimators, namely Engle (2002) Dynamic Conditional Correlation model, in order to compute time-varying conditional correlations between asset returns. The first sub-section provides a short outline of this econometric framework. The latter sub-section presents parameters estimates and analyzes pair-wise correlation patterns between asset returns.

\subsection{Engle (2002) Dynamic Conditional Correlation Model}

Let $r_{t}=\left(r_{1 t}, \ldots, r_{n t}\right)$ represent a $(n \times 1)$ vector of financial assets returns at time $(\mathrm{t})$. Moreover, let $\varepsilon_{t}$ $=\left(\varepsilon_{1 t}, \ldots, \varepsilon_{n t}\right)$ be a $(n \times 1)$ vector of error terms obtained from an estimated system of mean equations for these return series.

Engle (2002) proposes the following decomposition for the conditional variance-covariance matrix of asset returns:

$$
H_{t}=D_{t} R_{t} D_{t}
$$

where $D_{t}$ is a $(n \times n)$ diagonal matrix of time-varying standard deviations from univariate Garch models, and $R_{t}$ is a $(n \times n)$ time-varying correlation matrix of asset returns $\left(\rho_{i j, t}\right)$.

The conditional variance-covariance matrix $\left(H_{t}\right)$ displayed in equation [1] is estimated in two steps. In the first step, univariate Garch $(1,1)$ models are applied to mean returns equations, thus obtaining conditional variance estimates for each financial asset $\left(\sigma^{2} i t\right.$; for $\left.i=1,2, \ldots . ., n\right)$, namely:

$$
\sigma^{2}{ }_{i t}=\sigma^{2} u_{i t}\left(1-\lambda_{1 i}-\lambda_{2 i}\right)+\lambda_{1 i} \sigma^{2}{ }_{i, t-1}+\lambda_{2 i} \varepsilon^{2}{ }_{i, t-1}
$$


where $\sigma^{2}$ Uit is the unconditional variance of the $i$ th asset return, $\lambda_{1 i}$ is the volatility persistence parameter, and $\lambda_{2 i}$ is the parameter capturing the influence of past errors on the conditional variance.

In the second step, the residuals vector obtained from the mean equations system $\left(\varepsilon_{t}\right)$ is divided by the corresponding estimated standard deviations, thus obtaining standardized residuals (i.e., $u_{i t}=$ $\varepsilon_{i t} / \sqrt{\sigma_{i, t}^{2}}$ for $\left.\mathrm{i}=1,2, \ldots . ., n\right)$, which are subsequently used to estimate the parameters governing the time-varying correlation matrix.

More specifically, the dynamic conditional correlation matrix of asset returns may be expressed as:

$$
Q_{t}=\left(1-\delta_{1}-\delta_{2}\right) \bar{Q}+\delta_{1} Q_{t-1}+\delta_{2}\left(u_{t-1} u_{t-1}^{\prime}\right)
$$

where $\overline{\mathrm{Q}}=\mathrm{E}\left[u_{t} u_{t}^{\prime}\right]$ is the $(n \times n)$ unconditional covariance matrix of standardized residuals, and $\delta_{1}$ and $\delta_{2}$ are parameters (capturing, respectively, the persistence in correlation dynamics and the impact of past shocks on current conditional correlations). ${ }^{2}$

\subsection{Model Estimation and Dynamic Conditional Correlation Patterns}

The econometric framework summarized by Equations (1)-(3) was applied to gold, oil, and exchange rate returns.

After a preliminary data inspection, and in line with many contributions relying on this approach (see e.g., Ding and Vo (2012) and Jain and Biswal (2016) with regards to "safe haven" assets), a VAR(1) specification was selected to model the mean returns equation system. Alternative filtering procedures (such as an $\mathrm{AR}(1)$ specification for return series) produced substantially identical results.

The VAR(1) specification was selected on the basis of the Akaike Information Criterion (AIC) and of Likelihood Ratio tests against higher-order VAR models. Diagnostic tests on residuals from the $\operatorname{VAR}(1)$ specification never rejected the null of absence of serial correlation, while rejecting the normality assumption. This rejection was consistent with the preliminary data analysis, where the Jarque and Bera (1980) statistics turned out to be strongly significant.

These departures from normality have relevant implications on the distributional assumptions underlying the Multivariate Garch DCC model. More specifically, instead of relying on the standard Gaussian assumption (as in Engle (2002) seminal model), it is advisable to assume a Multivariate $\mathrm{t}$-distribution in order to better capture the fat-tailed nature of asset returns. This is the approach taken in the present paper. ${ }^{3}$

With regards to parameters, conditional volatility coefficients were unrestricted, and assumed different for each asset (see Equation (2)). Conditional correlation coefficients were unrestricted as well, although a common correlation structure was imposed in model's estimation (see Equation (3)).

The Maximum Likelihood estimator converged after 48 iterations and relied on 216 observations (20 observations were used to initialize the recursions).

Table 3 contains the results.

2 This multivariate Garch DCC model does not consider cross influences from other related dependent variables in the conditional variance and co-variance equations. As suggested by an anonymous referee, this is a shortcoming of this econometric approach, particularly if high co-movements exist among financial assets. The concluding section outlines other potential extensions of this econometric framework related to the present empirical investigation.

3 Note that Engle's original two-step procedure is no longer applicable under this alternative distributional assumption, and the Maximum Likelihood approach relies on a more efficient algorithm involving a simultaneous estimation of all model's parameters and an additional degrees of freedom parameter referring to the Multivariate Student distribution. 
Table 3. Multivariate Garch (1,1)-Dynamic Conditional Correlation (DCC) Model. Sample: 2000m112018m10 (216 Observations).

\begin{tabular}{cccc}
\hline Parameters & Estimate & Standard Error & T-Ratio [Prob.] \\
\hline$\lambda_{1 G}$ & $0.653^{* * *}$ & 0.178 & $3.66[0.000]$ \\
$\lambda_{1 O}$ & $0.699^{* * *}$ & 0.131 & $5.30[0.000]$ \\
$\lambda_{1 S}$ & $0.799^{* * *}$ & 0.139 & $5.73[0.000]$ \\
$\lambda_{2 G}$ & $0.138^{* *}$ & 0.062 & $2.20[0.028]$ \\
$\lambda_{2 O}$ & $0.207^{* * *}$ & 0.077 & $2.67[0.008]$ \\
$\lambda_{2 S}$ & $0.108^{* *}$ & 0.054 & $1.99[0.0048]$ \\
$\delta_{1}^{* *}$ & $0.978^{* *}$ & 0.016 & $57.8[0.000]$ \\
$\delta_{2}$ & $0.014^{* *}$ & 0.006 & $2.16[0.032]$ \\
$\mathrm{df}^{* * *}$ & $7.423^{* * *}$ & 1.643 & $4.51[0.000]$
\end{tabular}

Maximized Log-Likelihood: 1040.8

\footnotetext{
***: Significant at a $1 \%$ level; ${ }^{* *}$ : Significant at a $5 \%$ level. $\lambda_{1}, \lambda_{2 i}$ : Volatility parameters (assumed different for each asset) from univariate Garch equations: See Equations (2). $\delta_{1}, \delta_{2}$ : Correlation parameters (assumed equal for all asset returns): See Equation (3). df: Degrees of freedom parameter for the multivariate t-distribution.
}

All parameters were statistically significant, in most cases at the $1 \%$ significance level. Garch $(1,1)$ parameters for conditional variances were always positive; moreover, their sums $\left(\lambda_{1 i}+\lambda_{2 i}\right)$ were relatively close to 1 , particularly in the case of exchange rate returns (0.907) and oil returns (0.906). These results document the existence of stable time-varying volatility processes for all asset returns, although conditional volatilities displayed a high degree of persistence, particularly in the case of oil and Swiss Franc returns.

Turning to DCC parameters, in line with univariate Garch results, the common correlation structure displays a high degree of persistence. This correlation structure appeared mostly driven by lagged correlation dynamics $\left(\delta_{1}=0.978\right)$. However, the positive and statistically significant estimate for $\delta_{2}$ points out that also past shocks impart an appreciable effect on the time-varying correlation pattern of asset returns. The estimated degrees of freedom parameter $(\mathrm{df}=7.42)$ suggests that a multivariate $t$ distribution is appropriate to capture the not normal nature of assets returns.

Overall, these results imply that the proposed model represents an accurate description of the data generating process for filtered return series, and a reliable econometric framework to explore the nature of their pair-wise dynamic correlations. ${ }^{4}$

A major advantage of Multivariate Garch DCC models is to provide a straightforward framework to extract dynamic correlations for multiple assets inside a parsimonious parameter set up.

Figure 4 illustrates the estimated correlation coefficients between gold, oil, and Swiss Franc returns.

4 Further support to this model comes from a conditional evaluation procedure based on probability integral transform estimates. Under the null hypothesis of correct model specification, these estimates are serially uncorrelated and uniformly distributed in the $(0,1)$ range. A Lagrange Multiplier test for serial correlation, and a Kolmogorov-Smirnov test for uniform distribution of probability transform estimates show that this is actually the case, thus supporting the validity of the estimated model (further details available on request). 


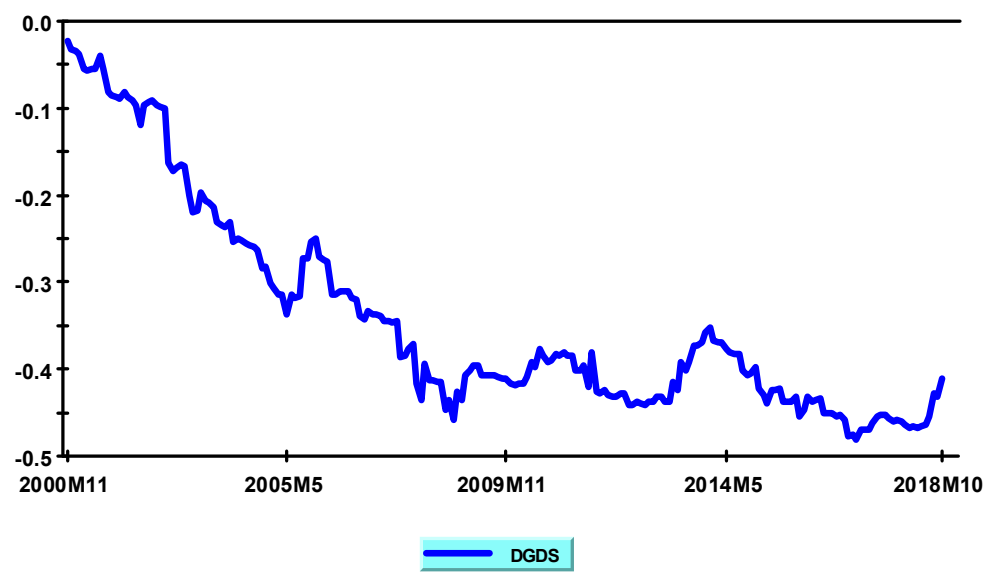

(a): Conditional correlation between Gold and Swiss Franc returns

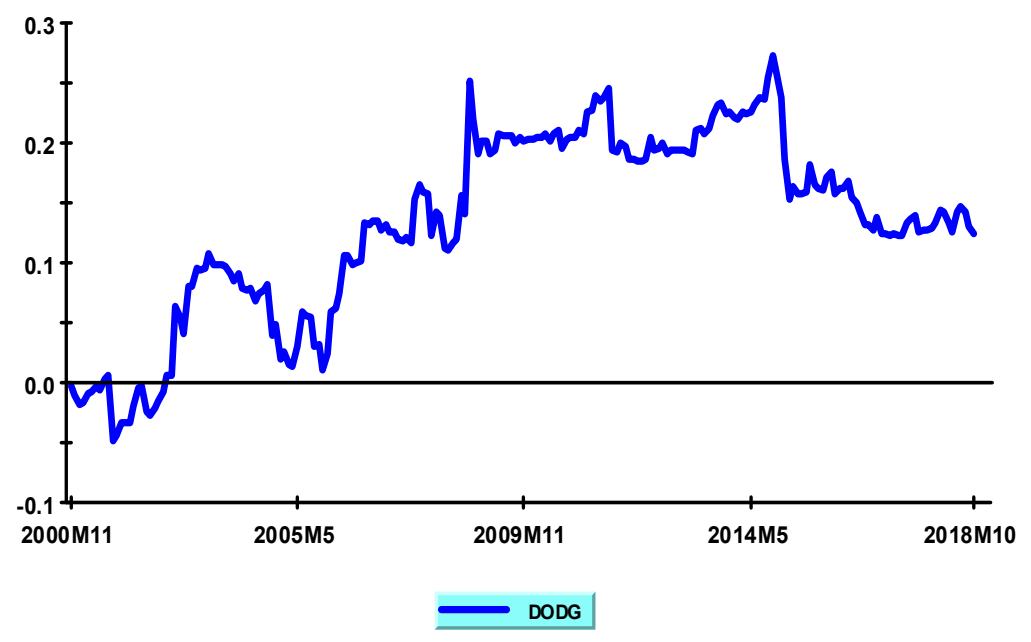

(b): Conditional correlation between Oil and Gold returns

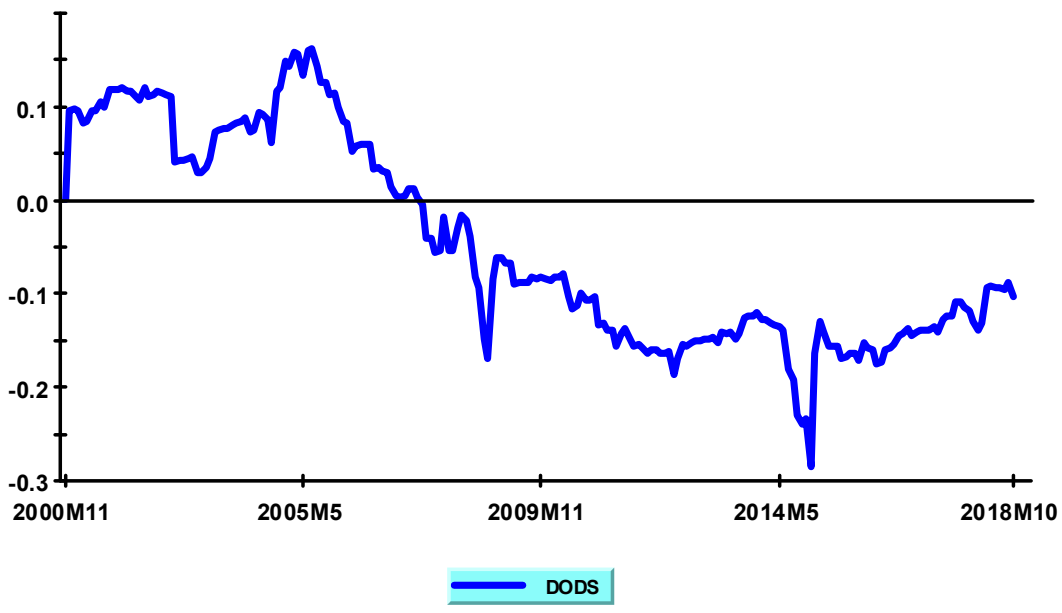

(c): Conditional correlation between Oil and Swiss Franc returns

Figure 4. Pair-wise dynamic conditional correlations. 
Visual inspection of Figure 4 yields some interesting insights. ${ }^{5}$ One relevant feature is that all pair-wise correlations exhibited an increasing long-run trend. This trend was stronger in the DG/DS case (starting from values around zero and reaching values around -0.4 at the end of the sample); on the other hand, this trend was relatively less intense for DO/DS and DO/DG correlations (both starting from values around zero and reaching, respectively, maximum values of -0.3 and +0.3 during the second half of 2014).

The estimated model therefore documented a significant tendency for these "safe haven" assets to increase their return co-movements during the last two decades.

A further interesting finding is related to the short-run dynamics of time-varying correlations. The analysis included many episodes of financial crisis, both at a global or continental level, and involving single countries. Starting with the well-known global financial crisis (2007-2009) and Eurozone debt crisis (2010-2012), this period includes many other relevant episodes of financial turmoil. These further episodes comprise: The Russian financial crisis (2014-2015), driven by the sharp oil price fall in 2014, and resulting in a large Russian Ruble devaluation and a huge stock market decline; the Chinese stock market crisis (2015) caused by the burst of a domestic stock market bubble in June 2015; and the Turkish currency and debt crisis (2018), mostly generated by an excessive current account deficit, and leading to large devaluation waves of the domestic currency.

In this perspective, a closer look at Figure 4 reveals that, for all conditional correlation pairs, the tendency towards stronger assets return co-movements were notably higher during all these financial crises episodes.

Consider, for instance, the DG-DS plot (Figure 4, upper section (a)). A strong increase in the conditional correlation between gold and Swiss Franc returns was apparent during the period corresponding to the global financial crisis (2007M8-2009M5), when this variable reached a relative minimum in August 2008. After a partial recovery in subsequent months, this correlation again followed a clear downward trend (thus capturing an increase in gold/Swiss Franc returns correlation) during most of the period corresponding to the Eurozone debt crisis (2010M1-2012M6). This movement was subsequently reversed during the tranquil phase corresponding to the year 2014, whereas the Russian financial crisis (2014M2-2015M2) and the Chinese stock market crisis (2015M6-2015M10) were once again associated with strong increases in conditional correlations, as documented by the low negative values reached in 2015.

The remaining correlations (DO-DG; DO-DS) displayed similar short-run patterns, since all major spikes in these variables were systematically associated with financial crises episodes.

On the whole, this visual evidence is consistent with a basic feature characterizing "safe haven" assets, that is to provide hedging benefits in periods of market turbulence. The increased return co-movements can be interpreted in terms of global portfolio shifts from traditional asset classes towards safer financial instruments in times of particular market stress. Since these portfolio shifts simultaneously increase the demand for "safe haven" assets, this tends to increase their returns correlations during crisis episodes.

To sum up, the Multivariate Garch model estimated in this section conveys two main results:

1. The last two decades witnessed a long-run trend of increased returns correlations between major "safe haven" assets;

5 With reference to Figure 4: DG-DS indicates pair-wise correlations between gold and Swiss Franc returns; DO-DS indicates pair-wise correlations between oil and Swiss Franc returns; DO-DG indicates pair-wise correlations between oil and gold returns. In order to properly interpret these plots, it must be remembered that a decrease in the Swiss Franc/USD exchange rate level corresponds to a Swiss Franc appreciation, thus generating an increase in Swiss Franc returns (see Section 2). For this reason, negative values for pair-wise correlations involving Swiss Franc returns (i.e., negative values for DO/DS and DG-DS) correspond to positive correlations between these asset returns. 
2. Focusing on periods of market stress, the "safe haven" properties of these assets consistently materialized, both during global or international financial crises episodes, and during "local" financial turmoil limited to single countries.

Drawing on this evidence, the next section explores the determinants of these time-varying conditional correlations, analyzing both the influence of various financial crises episodes and that of some potentially relevant macroeconomic variables.

\section{Determinants of Dynamic Conditional Correlations}

This section investigates some factors potentially affecting the evolution of conditional correlations among "safe haven" assets. The analysis proceeds in two steps. First, it provides some quantitative estimates about the impact of specific crises episodes. Second, it explores to what extent dynamic conditional correlations were significantly affected by some key macroeconomic variables related to the degree of international investors' confidence.

\subsection{Dynamic Conditional Correlations and Financial Crises}

The impact of financial turmoil on time-varying conditional correlations is explored in various contributions. The bulk of these analyses, however, concentrates on currency and stock markets, whereas "safe haven" financial assets have rarely been investigated.

The evidence from foreign exchange markets usually points out a significant effect for all crisis episodes. Tamakoshi and Hamori (2014) explored the time-varying linkages among some outstanding exchange rates against the USD. They reported a significant impact of the global financial crisis and of the Eurozone debt crisis on most, although not all, conditional correlations. A more homogenous empirical evidence was obtained in Karfakis and Panagiotidis (2015) where the Greek debt crisis emerged as the most significant covariate in quantile regressions involving all pair-wise exchange rates correlations.

The empirical evidence is more variegated in the case of stock markets. Syllignakis and Kouretas (2011) documented a significant effect of the 2008 stock market crash for seven stock markets of Central and Eastern European countries, whereas no significant effects were detected for previous crisis episodes (Asian financial crisis, dot-com bubble). Focusing on conditional correlation between BRICS stock markets and oil/gold future prices, Kang et al. (2016) reported a relevant effect of the dot-com bubble, a non-significant effect of the global financial crisis, and a slightly significant effect of the Eurozone sovereign debt crisis.

Bedoui et al. (2018) is the only recent contribution analyzing "safe haven" financial assets. These authors proposed nested copula based Garch models to study conditional dependence structures and, in line with the visual evidence discussed in the previous section, documented significant increases in asset co-movements both during the 2007/2009 global financial crisis and in the subsequent "post crisis" period. A drawback of this paper is that the period subsequent to the global financial crisis was treated as a unified time frame, thus disregarding the impact of latest financial turmoil.

This section contributes to the literature providing a more detailed information about the impact of all financial crises occurring over the last two decades on time-varying correlations.

In line with most applied research, the analysis relies on a regression approach with crises dummies for each financial turmoil episode (see, e.g., Syllignakis and Kouretas 2011; Tamakoshi and Hamori 2014; Kang et al. 2016).

More formally, denoting the time-varying returns correlation between asset $(i)$ and asset $(j)$ at time $t$ with $\rho_{i j, t}$, the following regression equation is estimated for each pair-wise conditional correlation:

$$
\rho_{i j, t}=\omega+\sum_{k=1}^{n} \gamma_{k} \operatorname{Dum}_{k, t}+\varepsilon_{i j, t}
$$


where $\omega$ and $\gamma_{k}$ are parameters, $\operatorname{Dum}_{k, t}$ is a dummy variable referring to a specific financial crisis episode, and $\varepsilon_{i j, t}$ is a disturbance term.

Since the estimation period includes five financial crises episodes, the $\mathrm{k}$ index goes from to one to five in equation [4]. ${ }^{6}$

The dummy variables included in equation [4] are defined as follows:

- Dum1: Global Financial Crisis (1 from 2007M8 to 2009M5; 0 elsewhere);

- Dum2: Eurozone Debt Crisis (1 from 2010M1 to 2012M6; 0 elsewhere);

- Dum3: Russian Financial Crisis (1 from 2014M12 to 2015M2; 0 elsewhere);

- Dum4: Chinese Stock Market Crisis (1 from 2015M6 to 2015M10; 0 elsewhere);

- Dum5: Turkish Financial Crisis (1 from 2018M3 to 2018M8; 0 elsewhere).

These dummy variables alternate between 1 and 0 depending on the existence of "crises" and "non-crises" periods. The selection of crises periods relies on various references from the literature, and on the main events characterizing the beginning and the end of financial turmoil episodes.

With regards to the global financial crisis, August 2007 is usually regarded as its starting date (see, among others, Casarin et al. 2018), due to the first signs of trouble in the US housing market, the French bank BNL Paribas suspension of three funds investing in the US mortgage market, and the FOMC first reduction in the Fed funds rate in response to liquidity and confidence problems. The end is usually placed towards the end of the first half of 2009 (Bordo and Landon-Lane 2010), and the selection of May 2009 reflects a full stabilization of the LIBOR-OIS spread as documented in Bernanke et al. (2018). ${ }^{7}$

The dummy for the Eurozone debt crisis reflects the observed spreads between 10-year sovereign bond yields of European countries (France, Greece, Ireland, Italy, Portugal, Spain) against Germany. As documented in Lane (2012) (see ibid. Figure 2), significant increases in these spreads were apparent since January 2010 (thus signaling the beginning of speculative attacks on European public debts), while these tendencies disappeared at mid-2012.

The remaining financial crises displayed a shorter length.

The Russian crisis, driven by economic sanctions for the military intervention in Ukraine and sharp oil price declines in the second half of 2014, displayed its major effects on international financial markets between December 2014 and February 2015. This period was characterized by a sharp Ruble devaluation against major currencies, huge rises in domestic interest rates, large foreign reserves declines, and an all-time-low in the domestic stock price index.

The Chinese stock market crisis began in June 2015 with the burst of the domestic stock price bubble, which determined a Shangai Composite Index increase of about 150\% from mid-2014 to mid-2015. This stock market crash displayed all the main features of classical financial crises described in Kindleberger (1978): irrational exuberance of investors causing share prices to progressively diverge from values consistent with market fundamentals, large presence of novice investors making highly leveraged purchases with borrowed money, and loose financial regulations (a progressive relaxation of restrictions on margin trading occurred over the preceding five years). In line with the consensus view, the end of this crisis was set at October 2015, when the Shangai Composite Index oscillated around minimum values, before exhibiting a mild recovery in subsequent months (see, Zeng et al. 2016, Figure 1, p. 413).

The Turkish financial crisis was essentially a currency and balance of payment crisis, caused by Turkey's excessive current account deficit and the large share of foreign currency denominated external

6 The estimation period for Equation (4) ranges from 2000M11 to 2018M10. The dot-com financial crisis is not included since, according to the bubble monitoring approach outlined in Phillips and Shi (2018), this financial crisis originated in 1995M8 and ended in 2000M11.

7 This document is a chart book about the global financial crisis produced under the supervision of Ben Bernanke, Timothy Geithner and Henry Paulson. It identifies three distinct phases of this crisis: increasing stress, early escalation, panic and resolution. Overall, the starting and ending dates indicated in the document (see ibid. page 17) match those corresponding to the dummy variable (Dum1) used in the present paper. 
debt. This crisis manifested predominantly with large devaluation waves of the domestic currency, prompted both by Turkey's structural economic imbalances and by President Erdogan's unorthodox interest rate policy. Accordingly, the starting date was set in March 2018 (first devaluation pressures on foreign exchange markets), and the ending date was set in August 2018 (record devaluation level of the Turkish Lira against the USD).

Each financial crisis episode was expected to significantly contribute, on average, to increase conditional dependencies between "safe haven" asset returns.

The economic intuition is the following. A typical feature of "safe haven" assets is to protect investors' portfolios, particularly during financial turmoil episodes when more traditional asset classes experience severe losses due to highly negative developments in the macroeconomic and financial outlook. Therefore, during a financial crisis, when traditional asset classes are negatively affected by sequences of "bad news", massive portfolio shifts towards alternative financial instruments simultaneously pull up their prices and, hence, time-varying correlations between these asset returns. An analogous mechanism may operate in the reverse direction, again generating an increase in "safe haven" assets returns correlations. ${ }^{8}$

To sum up, economic intuition suggests that, although each "safe haven" asset reflects specific economic influences, return co-movements between these financial instruments may be expected to rise, on average, during financial crises episodes. The evidence reported in Bedoui et al. (2018) for the global financial crisis supports the above intuition.

Equation (4) is estimated for each pair-wise conditional correlation involving gold, oil, and Swiss Franc returns. Table 4 summarizes the empirical evidence. These results were obtained applying the Newey and West (1987) consistent covariance matrix estimator, thus making parameters estimates robust to the existence of autocorrelation and heteroscedasticity in regression residuals.

Table 4. Dynamic conditional correlations and financial crises. Sample: 2000m11-2018m10 (216 Observations).

\begin{tabular}{cccc}
\hline Parameters & DGDS & DODG & DODS \\
\hline$\omega$ & $-0.31^{* * *}$ & $0.11^{* * *}$ & -0.019 \\
& $(-8.47)$ & $(5.05)$ & $(-0.59)$ \\
$\gamma_{1}$ & $-0.098^{* * *}$ & $0.052^{* *}$ & -0.041 \\
& $(-2.59)$ & $(2.04)$ & $(-1.21)$ \\
$\gamma_{2}$ & $-0.097^{* * *}$ & $0.096^{* * *}$ & $-0.113^{* * *}$ \\
& $(-2.62)$ & $(4.22)$ & $(-3.21)$ \\
$\gamma_{3}$ & $-0.107^{* * *}$ & $0.081^{* * *}$ & $-0.173^{* * *}$ \\
& $(-2.92)$ & $(3.65)$ & $(-4.94)$ \\
$\gamma_{4}$ & $-0.123^{* * *}$ & $0.055^{* *}$ & $-0.144^{* * *}$ \\
& $(-3.36)$ & $(2.54)$ & $(-4.43)$ \\
$\gamma_{5}$ & $-0.147^{* * *}$ & 0.028 & $-0.080^{* *}$ \\
$\mathrm{R}^{2}$ & $(-4.05)$ & $(1.32)$ & $(-2.48)$ \\
\hline
\end{tabular}

Estimated equation: $\rho_{i j, t}=\omega+\sum_{\mathrm{k}=1}^{\mathrm{n}} \gamma_{k}$ Dum $\mathrm{m}_{k, t}+\varepsilon_{i j, t .} \gamma_{1}$ : Parameter relative to the effect of Global Financial Crisis;

$\gamma_{2}$ : Parameter relative to the effect of Eurozone Debt Crisis; $\gamma_{3}$ : Parameter relative to the effect of Russian Financial Crisis; $\gamma_{4}$ : Parameter relative to the effect of Chinese Stock Market Crisis; $\gamma_{5}$ : Parameter relative to the effect of Turkish Financial Crisis. OLS estimation; Newey and West (1987) heteroscedasticity, and autocorrelation consistent estimates of the variance-covariance matrix of parameters. $t$-statistic in parentheses below estimated parameters values. $^{* * *}$ : Significant at a $1 \%$ level; ${ }^{* *}$ : Significant at a $5 \%$ level.

In order to properly interpret the results, it must be remembered that in the case of DODG (oil-gold returns correlation) positive estimates of $\gamma_{k}$ parameters point out a positive effect of financial crises

During a financial crisis, a temporary sequence of "good news" may generate a reverse portfolio shift producing a temporary recovery in more traditional asset classes. In this case, massive flows of liquidity out of "safe haven" assets produce a simultaneous decrease in "safe haven" assets returns and hence, once again, an increase in their conditional correlations. 
on time-varying correlations. The reverse holds in the remaining cases (DGDS, DODS): Negative $\gamma_{k}$ estimates now point out positive effects of financial crises, given the definition of Swiss Franc returns.

The results of Table 4 confirm those obtained in Bedoui et al. (2018) for the 2007-2009 global financial crisis and are fully in line with economic intuition.

The significant increase in conditional correlations between "safe haven" assets during financial crises stands out as an important empirical regularity of the last two decades. As documented in Table 4, this regularity holds for all pair-wise correlations and all crises periods.

Although the $\mathrm{R}^{2}$ values for estimated equations were not particularly high, the explicative power of Equation (4) was satisfactory, taking into account the nature of dependent variables and the absence of specific economic or financial variables on the right-hand side of this equation.

Focusing on Equation (4) in more detail, all estimated coefficients were statistically significant, in most cases at a $1 \%$ confidence level. All coefficients, moreover, had correct expected signs (negative for pair-wise correlations involving exchange rate returns, and positive for DODG), pointing out the significant impact of each financial crisis on the increase in conditional correlations.

The quantitative influence of various crises episodes was quite homogeneous with regards to DGDS and DODG. In these cases, the estimated $\gamma_{k}$ coefficients were broadly similar for the two most relevant financial crises (global financial crisis, Eurozone debt crisis) and subsequent crises episodes. A greater impact of latest crises episodes, and in particular of the Russian financial crisis, was instead documented for DODS. ${ }^{9}$

To sum up, the empirical evidence of this section points out that gold, oil, and the Swiss Franc maintained their "safe haven" properties over the last two decades. All pair-wise correlations were significantly affected both by long-lasting and acute crises episodes and by shorter and relatively less intense financial turmoil.

Notwithstanding the significant impact of various crises episodes, hedging opportunities among alternative "safe haven" assets were still present, according to this empirical investigation.

Empirical estimates of Section 3 document that the gold-Swiss Franc correlation increased from about 0 to 0.5 during the sample period, whereas the remaining correlations never exceeded 0.3 (see Figure 4). These financial assets therefore remain de-correlated to a large extent, notwithstanding the contrarian influence exerted by various crises episodes. Therefore, for smart international investors, significant hedging opportunities persist, not only between "safe haven" and more traditional financial assets, but also with reference to the optimal portfolio allocation among alternative "safe haven" assets.

\subsection{Dynamic Conditional Correlations and Macroeconomic Variables}

Various contributions explore the influence of macroeconomic and financial variables on time-varying conditional correlations.

With regards to international stock markets, Cai et al. (2009) documented a significant influence of cyclical fluctuations in inflation rates and stock volatility on asset correlations of major advanced countries, while Syllignakis and Kouretas (2011) provided analogous evidence for Central and Eastern European economies. A significant influence of economic and financial variables was documented for many other financial markets (see, e.g., (Bashiri Behmiri et al. 2019) with regards to commodity futures markets).

Focusing on conditional dependencies among "safe haven" financial assets, however, existing contributions are much scarcer. Bedoui et al. (2018) reported, in line with the evidence of the present paper, that oil and gold conditional correlation increased during the global financial crisis. These

9 The large $\gamma_{3}$ estimate obtained in this case is mainly explained by the large oil price drop at the end of 2014 , occurred during the Russian financial crisis, and by a temporary weakness of the Swiss Franc during the same period. These movements are captured by the huge negative spike (denoting an increase in the oil/Swiss Franc returns correlation) for DODS in December 2014 (see Figure 4c). 
authors suggest that "gold and oil positively influence each other, possibly because prices move in the same way with macroeconomic variables" (ibid., page 143), although they do not pursue further this line of research.

Poshakwale and Mandal (2016) is the only contribution systematically exploring the influence of macroeconomic and other variables on "safe haven" asset returns co-movements. These authors reported a variegated influence of macroeconomic and non-macroeconomic factors; moreover, they showed that a dynamic strategy incorporating information from these variables yielded better forecasts of future correlations, thus enhancing investor's optimal portfolio choices.

This section contributes to the applied literature on "safe haven" assets exploring the impact of some macroeconomic variables on dynamic correlations. Since the sample includes many financial crisis episodes, the variable selection concentrates on macroeconomic risk factors potentially displaying a major influence under frequent financial turbulences.

The macroeconomics risk factors considered are the following ${ }^{10}$ :

3. World Equity Risk Premium;

4. World Economic Policy Uncertainty;

5. US Economic Policy Uncertainty;

6. ECB-Systemic Stress Composite Indicator;

7. US Consumer Confidence Index.

The realized equity risk premium is defined as the excess return of equities over risk-free securities. The expected equity risk premium represents the compensation required by investors to hold risky assets. This series represents a classical proxy to measure the degree of risk aversion in applied financial economics. The world equity risk premium used in the present paper represents an average measure for all major world economic areas and therefore captures the perspective of a representative international investor on global financial markets. ${ }^{11}$

Economic policy uncertainty indexes are built to reflect the degree of uncertainty surrounding future economic policy developments, both at a single-country level and considering larger economic areas. These indexes basically rely on the counting of the number of newspapers articles containing the terms "uncertain" or "uncertainty", "economic" or "economy", and one or more policy-relevant term. In the case of the US index, the component related to the newspaper coverage about economic policy uncertainty is integrated with two additional components reflecting, respectively, the number of Federal tax code provisions set to expire in future years (fiscal policy uncertainty) and the disagreement among economic forecasters (macroeconomic uncertainty). See Baker et al. (2016) fur further methodological details.

The Composite Indicator of Systemic Stress is a new indicator of contemporaneous stress in the financial system introduced by the ECB with the aim of analyzing, monitoring, and controlling systemic risk (Hollo et al. 2012). From the methodological viewpoint, the main innovation of this indicator is the use of standard portfolio theory to aggregate five market-specific sub-indices into a single statistic summarizing the state of financial instability.

The US Consumer Confidence Index is an economic indicator published by the Conference Board reflecting the degree of optimism about the state of the US economy expressed through consumers saving and spending decisions. Since the US economy exerts a prominent influence on all major advanced economies, this paper focuses exclusively on this consumer confidence indicator. This index relies on monthly surveys of 5000 households with questions regarding current and short-term

10 All monthly series were obtained from Thomson Reuters-Datastream. Thomson Reuters codes are the following: World Equity Risk Premium (end-of-month data): WDASERP; World Economic Policy Uncertainty (mid-month data): WDEPUCUPR; US Economic Policy Uncertainty (mid-month data): USPUPOLR; ECB-Systemic Stress Composite Indicator: EMCISSI; US Consumer Confidence Index (s.a. data): USCNFCONQ.

11 The World Equity Premium series used in this paper ranges from very low values around $1.5 \%$ at the beginning of the sample, to record peaks above $7 \%$ during the global and Eurozone debt crises, and stabilizes around values of $4-5 \%$ thereafter. 
expected business conditions, current and short-term expected employment conditions, and total family income expected for the next six months.

In line with the analysis of the previous section, a regression approach was used to investigate the effect of these macroeconomic variables on time-varying conditional correlations. The estimated equation is then specified as follows:

$$
\rho_{i j, t}=\omega+\phi_{k}\left(\text { Macro }_{k}\right)+\varepsilon_{i j, t}
$$

where, as before, $\rho_{i j}$, denotes the time-varying conditional correlation between asset $(i)$ and asset $(j), \omega$ is a constant term, and $\phi_{k}$ is a coefficient relative to the impact of each single macro-variable $(k) .{ }^{12}$

Note that, differently from Section 4.1, the impact of different variables is analyzed separately in Equation (5). Financial crises represent, to a large extent, independent events, whereas clear interdependencies exist between some macro-variables studied in the present section. Therefore, a separate analysis for each macro-variable avoids multicollinearity problems in the estimate of Equation (5).

Expected signs of $\phi_{k}$ parameters are again related to portfolio shifts between traditional financial instruments and "safe haven" assets.

An increase in the world equity risk premium captures an increase in international investor's global risk aversion. This lower risk appetite is likely to induce a simultaneous portfolio shift towards "safe haven" assets, pulling up their prices and hence increasing their returns co-movements. Therefore, other things being equal, a higher world equity risk premium is expected to increase dynamic correlations.

Analogous effects can be posited as regards economic policy uncertainty indicators. An increase in these indicators points out a greater uncertainty surrounding future economic policy developments, thus signaling a greater policymaker's difficulty to tackle complex economic problems. At the macro level, higher economic policy uncertainty foreshadows declines in investments, output, and employment, as recently documented for the US and other major economies (Baker et al. 2016). The likely effect on global financial markets is therefore a simultaneous reduction in the degree of risk exposure to more traditional financial assets, generating again an increase in "safe haven" asset returns co-movements.

An increase in the consumer confidence indicator captures a more optimistic attitude of US consumers towards future developments of the US economy. At the macro level, this boost in consumers' confidence is associated with a better future economic outlook in the US and significant positive international spillovers. The effect of an increase of this indicator on global financial markets is therefore expected to operate in the reverse direction with respect to those previously discussed. A better international macroeconomic outlook should lower dynamic correlations due to a gradual portfolio rebalancing from "safe haven" assets towards more traditional financial instruments offering increased returns prospects. ${ }^{13}$

With regards to the ECB-Composite Indicator of Systemic Stress, there is currently no consensus in the literature about one commonly accepted definition of systemic risk (European Central Bank 2009). ${ }^{14}$ The intrinsic nature of this variable makes this typology of risk non-diversifiable (Ben-Horim and Levy 1980), so that previous arguments relying on portfolio shifts among alternative asset categories can

$12 \phi_{k}$ coefficients are defined consistently with the macro-variables list provided in the main text. Therefore, $\phi_{1}$ refers to the effect of the world equity risk premium on conditional correlations, $\phi_{2}$ to the effect of world economic uncertainty, and so on.

13 Lower asset returns co-movements as a consequence of better macroeconomic prospects imply a gradual, not simultaneous, liquidity outflow from "safe haven" assets towards bonds and equities. This appears as a quite realistic process in the presence of a better expected macroeconomic outlook. Differently from previously described cases, in fact, the need to quickly re-optimize portfolio allocations appears less urgent in this specific case.

14 Theoretical and empirical research made nonetheless consistent progresses in recent years analyzing a wide set of factors triggering systemic risk, such as contagion effects, macroeconomic shocks, or endogenous builds-up of financial market unbalances. De Bandt and Hartmann (2000) provide a very accurate survey about systemic risk. 
hardly be applied in this case. Strictly speaking, therefore, no significant effect of this risk indicator should be expected in the context of the present empirical investigation.

It must, however, be remembered that "safe haven" assets represent a special category of financial assets, and that this systemic risk indicator provides a real-time monitoring about the overall stability of the financial system. In this perspective, an increase in the ECB-Composite Indicator of Systemic Stress could generate some positive effect on dynamic conditional correlations, mainly as a result of "flight-to-quality" emotional reactions of global international investors in the presence of greater overall financial instability.

Table 5 summarizes the empirical evidence from OLS estimates of Equation (5). These results were again obtained applying the Newey and West (1987) consistent covariance matrix estimator.

Table 5. Dynamic conditional correlations and macro-variables. Sample: 2000m11 - 2018m10 (216 Observations).

\begin{tabular}{|c|c|c|c|c|c|c|c|c|c|}
\hline Macrovariables & & DGDS & & & DODG & & & DODS & \\
\hline $\begin{array}{l}\text { World Equity } \\
\text { Risk Premium }\end{array}$ & $\begin{array}{c}\omega \\
-0.54 \\
(-0.71)\end{array}$ & $\begin{array}{c}\phi_{1} \\
-0.73^{* * *} \\
(-4.35)\end{array}$ & $\begin{array}{c}\mathrm{R}^{2} \\
0.528\end{array}$ & $\begin{array}{c}\omega \\
-0.05 \\
(-1.59)\end{array}$ & $\begin{array}{c}\phi_{1} \\
0.48^{* * *} \\
(5.85)\end{array}$ & $\begin{array}{c}\mathrm{R}^{2} \\
0.574\end{array}$ & $\begin{array}{c}\omega \\
0.24^{* * *} \\
(5.62)\end{array}$ & $\begin{array}{c}\phi_{1} \\
-0.73^{* * *} \\
(-6.99)\end{array}$ & $\begin{array}{c}R^{2} \\
0.654\end{array}$ \\
\hline $\begin{array}{l}\text { World Econ. } \\
\text { Policy } \\
\text { Uncertainty }\end{array}$ & $\begin{array}{c}\omega \\
-0.22^{* * *} \\
(-6.07)\end{array}$ & $\begin{array}{c}\phi_{2} \\
-1.02 * * * \\
(-6.11)\end{array}$ & $\begin{array}{c}\mathrm{R}^{2} \\
0.149\end{array}$ & $\begin{array}{c}\omega \\
0.08^{* * *} \\
(2.76)\end{array}$ & $\begin{array}{c}\phi_{2} \\
0.39^{* *} \\
(2.10)\end{array}$ & $\begin{array}{c}\mathrm{R}^{2} \\
0.054\end{array}$ & $\begin{array}{c}\omega \\
0.10^{* *} \\
(2.47)\end{array}$ & $\begin{array}{c}\phi_{2} \\
-1.30 * * * \\
(-4.97)\end{array}$ & $\begin{array}{c}\mathrm{R}^{2} \\
0.292\end{array}$ \\
\hline $\begin{array}{l}\text { Systemic Stress } \\
\text { Comp. Indicator }\end{array}$ & $\begin{array}{c}\omega \\
-0.31 * * * \\
(-8.57)\end{array}$ & $\begin{array}{c}\phi_{4} \\
-0.15^{* *} \\
(-2.24)\end{array}$ & $\begin{array}{c}\mathrm{R}^{2} \\
0.044\end{array}$ & $\begin{array}{c}\omega \\
0.10^{* * *} \\
(4.67)\end{array}$ & $\begin{array}{c}\phi_{4} \\
0.13^{* *} \\
(2.74)\end{array}$ & $\begin{array}{c}\mathrm{R}^{2} \\
0.083\end{array}$ & $\begin{array}{c}\omega \\
-0.02 \\
(-0.59)\end{array}$ & $\begin{array}{c}\phi_{4} \\
-0.13 \\
(-1.58)\end{array}$ & $\begin{array}{c}\mathrm{R}^{2} \\
0.043\end{array}$ \\
\hline
\end{tabular}

Estimated equation: $\rho_{i j, t}=\omega+\phi_{k}\left(M_{a c r o}\right)+\varepsilon_{i j, t}$. OLS estimation; Newey and West (1987) heteroscedasticity, and autocorrelation consistent estimates of the variance-covariance matrix of parameters. $t$-statistic in parentheses below

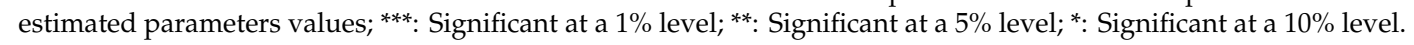

A proper interpretation of estimated $\phi_{k}$ parameters requires, consistently with Section 4.1 , to remember the definition of Swiss Franc returns. Accordingly, in pair-wise correlations involving Swiss Franc returns (DGDS, DODS), negative $\phi_{k}$ estimates captured a positive effect of macro-variables on these conditional correlations (an increase in each macro-variable increases conditional correlations). The reverse holds in the remaining case (DODG): positive $\phi_{k}$ estimates pointed out a positive effect of macro-variables on the oil-gold returns correlation.

Almost all estimated $\phi_{k}$ coefficients were strongly significant, in most cases at the $1 \%$ confidence level. Moreover, all $\phi_{k}$ coefficients displayed their expected signs, suggesting that the economic intuition underlying the previous discussion is correct.

Let us now address the empirical evidence in more detail.

One important result is that the world equity risk premium can be singled out as the most relevant macro-variable affecting all conditional correlations (Table 5, first row). Quantitative estimates of $\phi_{1}$ documented the positive and significant impact of this variable: an increase in the world equity risk premium significantly increased all pair-wise dynamic correlations between "safe haven" financial assets. Moreover, focusing on R-squared values, the explicative power of equations including the world equity risk premium was by far the largest than any other estimated equation. These results document that global risk aversion was the main driving force of "safe haven" assets co-movements during the period examined. A lower risk appetite during financial crises episodes induced massive simultaneous portfolio shifts towards these assets, thus increasing their return correlations. These results, together with the evidence about the impact of financial crises provided in the previous section, document that gold, the Swiss Franc, and oil retained their "safe haven" features during the last two decades. 
A latter important influence stems from economic policy uncertainty indicators. Estimated $\phi_{2}$ and $\phi_{3}$ coefficients were always strongly significant, while the explicative power of corresponding equations remained relatively high, particularly with regards to oil/Swiss Franc return correlations (DODS). The quantitative influence exerted by these indicators was broadly similar, with a slight prevalence of the global economic policy indicator in terms of explicative power. On the whole, these findings document that uncertainty about future policy developments played a further important role in shaping global investors' asset allocation choices. Moreover, they document that the financial assets studied in this paper acted as powerful hedging instruments in the presence of increased economic policy instability.

Turning to the last two macro-variables, their influence appeared relatively more limited. With regards to US consumer confidence, the estimated coefficient $\left(\phi_{5}\right)$ was strongly significant only in the case of DODG (oil-gold correlation), whereas in the two remaining cases, it was either significant at the $10 \%$ level (DODS) or not significant (DGDS). Although the reported signs of $\phi_{5}$ suggested that better economic prospects tend to induce a gradual portfolio rebalancing out of "safe haven" assets, the intensity of this effect was clearly weaker and less pervasive with respect to previously examined indicators.

Finally, focusing on the ECB-Composite Indicator of Systemic Stress, only a modest influence was found for systemic risk. In one case (DODS), the $\phi_{4}$ coefficient was not statistically significant, whereas in the two remaining cases, it was significant at the $5 \%$ level. The magnitude of estimated $\phi_{4}$ parameters for pair-wise correlations with gold returns (DGDS, DODG) was always very low and the corresponding equations displayed, on average, a low explicative power. On the whole, these results are in line with a priori expectations and support the intrinsic non-diversifiable nature of systemic risk. The modest effects documented in pair-wise correlations involving gold returns (increasing correlations as a consequence of higher systemic risk) were consistent with small flight-to-quality effects in the presence of higher global financial instability.

To sum up, this section provides interesting insights about the influence of some relevant macro-variables on co-movements between "safe haven" assets. The world equity risk premium is the most important variable affecting global investors' portfolio choices; moreover, uncertainty indicators about US and global future economic policies were also found to exert significant effects on portfolio allocation choices between traditional and "safe haven" assets. The impact of consumers' confidence and systemic risk indicators instead appeared much more limited.

\section{Conclusions}

This paper focuses on three "safe haven" assets which have received wide attention in the recent applied literature (gold, Swiss Franc, and oil), and explores some statistical properties of these assets with a particular focus on their time-varying correlation patterns.

The influence of financial crises and macroeconomic variables on dynamic correlations between "safe haven" assets have seldom been explored. This represents one major drawback in the literature, since the last two decades witnessed many financial crises with important international spillover effects. Moreover, the impact of macroeconomic and financial variables on co-movements between "safe haven" asset returns is likely to be substantial, particularly if these variables reflect the degree of risk aversion, economic uncertainty, or the degree of confidence of economic agents.

In this perspective, this paper fills one relevant gap in the applied literature on "safe haven" assets, providing a thorough analysis about the determinants of their return co-movements during the last two decades.

The main empirical findings may be summarized as follows.

Financial crises produced a significant increase in all pair-wise correlations between "safe haven" assets. This influence is not limited to major financial turbulences (global financial crisis, Eurozone debt crisis), but involves all subsequent crises episodes (Russian financial crisis, Chinese stock market 
crisis, Turkish financial crisis). This pervasive effect of financial crises implies that gold, oil, and the Swiss Franc retained their "safe haven" status during the last two decades.

A latter important result refers to the effects of some outstanding macroeconomic variables. The world equity risk premium stands out as the most relevant variable affecting return co-movements. The impact of this risk aversion indicator on "safe haven" assets return co-movements is always large, and explains a consistent fraction of correlation patterns. Another noticeable influence stems from various economic policy uncertainty indicators, which played a further relevant role in shaping global investors asset allocation choices towards "safe haven" financial assets. The effects of other macroeconomic variables, such as consumer confidence or systemic stress indicators, are instead more limited. Overall, the empirical evidence for macroeconomic variables reiterates the features of gold, oil, and the Swiss Franc as important "safe haven" assets during the period examined.

This paper can be profitably extended along many research directions.

The robustness of results may be assessed using data sampled at higher frequencies (weekly, daily, intra-daily). Moreover, this analysis can be extended to other financial assets typically included in the "safe haven" category (US long-term government bonds, the Yen exchange rate, and other precious metals).

A further interesting research area is represented by the use of more sophisticated models to compute dynamic conditional correlations. Profitable research directions are represented by some extension of Engle (2002) seminal model, allowing for asymmetric responses in conditional variance and conditional correlations to negative returns, or allowing correlation dynamics to depend on asset variances through a threshold structure.

In a more general perspective, the development of powerful econometric techniques for the analysis of conditional correlation structures of a large number of assets remains on the top of the research agenda. Although plagued by the curse of dimensionality problem, this represents a crucial condition for a more accurate assessment of the hedging properties of "safe haven" assets against traditional financial instruments and the development of efficient dynamic asset allocation strategies.

Funding: This research received no external funding.

Acknowledgments: The author is thankful to the anonymous referees for very useful comments.

Conflicts of Interest: The author declares no conflict of interest.

\section{References}

Baker, Scott R., Nicholas Bloom, and Steven J. Davis. 2016. Measuring economic policy uncertainty. Quarterly Journal of Economics 131: 1593-636. [CrossRef]

Bashiri Behmiri, Niaz B., Matteo Manera, and Marcella Nicolini. 2019. Understanding dynamic conditional correlation between oil, natural gas and non-energy commodity futures markets. Energy Journal 40: 55-76. [CrossRef]

Baur, Dirk G., and Thomas K. McDermott. 2010. Is gold a safe haven? International evidence. Journal of Banking and Finance 34: 1886-98. [CrossRef]

Bedoui, Rihab, Sana Braeik, Stephane Goutte, and Khaled Guesmi. 2018. On the study of conditional dependence structure between oil, gold and USD exchange rates. International Review of Financial Analysis 59: 134-46. [CrossRef]

Ben-Horim, Moshe, and Haim Levy. 1980. Diversifiable risk and non-diversifiable risk: A pedagogical note. Journal of Financial and Quantitative Analysis 15: 289-97. [CrossRef]

Bernanke, Ben, Timothy Geithner, and Henry Paulson. 2018. Charting the Financial Crisis. Hutchins Center on Fiscal and Monetary Policy at Brookings, Yale School of Management Program on Financial Stability. Available online: https://www.brookings.edu (accessed on 24 February 2020).

Bordo, Michael D., and John S. Landon-Lane. 2010. The Global Financial Crisis of 2007-2008: Is It Unprecedented? NBER Working n.16589. Cambridge: NBER. [CrossRef]

Cai, Jije, Ray Chou, and Dan Li. 2009. Explaining international stock correlations with CPI fluctuations and market volatility. Journal of Banking and Finance 33: 2026-35. 
Campbell, John Y., Karine Serfaty-de Medeiros, and Luis M. Viceira. 2010. Global currency hedging. Journal of Finance 65: 87-121. [CrossRef]

Casarin, Roberto, Domenico Sartore, and Marco Tronzano. 2018. A Bayesian Markov-switching correlation model for contagion analysis on exchange rate markets. Journal of Business E Economic Statistics 36: 101-14.

Chua, Jess H., Gordon Sick, and Richard S. Woodward. 1990. Diversifying with gold stocks. Financial Analyists Journal 46: 76-79. [CrossRef]

Ciner, Cetin, Constantin Gurdgiev, and Brian M. Lucey. 2013. Hedges and safe havens: An examination of stocks, bonds, oil and exchange rates. International Review of Financial Analysis 29: 202-11. [CrossRef]

Creti, Anna, Marc Joëts, and Valerie Mignon. 2013. On the links between stock and commodity markets' volatility. Energy Economics 37: 16-28. [CrossRef]

De Bandt, Olivier, and Philipp Hartmann. 2000. Systemic Risk: A Survey. ECB Working Papers Series n. 35; Frankfurt: ECB.

Ding, Liang, and Minh Vo. 2012. Exchange rates and oil prices: A multivariate stochastic volatility analysis. Quarterly Review of Economics and Finance 52: 15-37. [CrossRef]

Economist. 2005. The Little yellow gold. The Economist Newspaper Limited, December 1.

Economist. 2009. Haring away. The Economist Newspaper Limited, February 29.

Engle, Robert. 2002. Dynamic conditional correlation: A simple class of multivariate generalized autoregressive conditional heteroscedasticity models. Journal of Business \& Economic Statistics 20: 339-50.

European Central Bank. 2009. The concept of systemic risk. Financial Stability Review. Available online: https://www.ecb.europa.eu/pub/pdf/fsr/art/ecb.fsrart200912_02.en.pdf (accessed on 24 February 2020).

Guidolin, Massimo, and Allan Timmermann. 2007. Asset allocation under multivariate regime switching. Journal of Economic Dynamics and Control 31: 3503-44. [CrossRef]

Holló, Daniel, Manfred Kremer, and Marco Lo Duca. 2012. CISS—A Composite Indicator of Systemic Stress in the Financial System. ECB Working Papers Series n. 1426; Frankfurt: ECB.

Hood, Matthew, and Farooq Malik. 2013. Is gold the best hedge and a safe haven under changing stock market volatility? Review of Financial Economics 22: 47-52. [CrossRef]

Jaffe, Jeffrey. 1989. Gold and gold stocks as investments for institutional portfolios. Financial Analysts Journal 45: 53-59. [CrossRef]

Jäggi, Adrian, Martin Schlegel, and Attilio Zanetti. 2019. Macroeconomic surprises, market environment, and safe-haven currencies. Swiss Journal of Economics and Statistics 155: 1-21. [CrossRef]

Jain, Anshul, and Pratap Biswal. 2016. Dynamic linkages among oil price, gold price, exchange rate, and stock market in India. Resources Policy 49: 179-85. [CrossRef]

Jarque, Carlos, and Anil K. Bera. 1980. Efficient tests for normality, homoscedasticity and serial independence of regression residuals. Economic Letters 6: 255-59. [CrossRef]

Kang, Sang Hoon, Ron McIver, and Seong-Min Yoon. 2016. Modeling time-varying correlations in volatility between BRICS and commodity markets. Emerging Markets Finance \& Trade 52: 1698-723.

Kang, Sang Hoon, Ron McIver, and Seong-Min Yoon. 2017. Dynamic spillover effects among crude oil, precious metal, and agricultural commodity futures markets. Energy Economics 62: 19-32. [CrossRef]

Karfakis, Costas, and Theodore Panagiotidis. 2015. The effects of global monetary policy and Greek debt crisis on the dynamic conditional correlations of currency markets. Empirica 42: 795-811. [CrossRef]

Kindleberger, Charles P. 1978. Manias, Panic, and Crashes: A History of Financial Crises. London: Macmillan Press.

Kugler, Peter, and Beatrice Weder. 2004. International portfolio holdings and Swiss Franc asset returns. Swiss Journal of Economics and Statistics 140: 301-25.

Lane, Philip R. 2012. The European sovereign debt crisis. Journal of Economic Perspectives 26: 49-68. [CrossRef]

Newey, Whitney K., and Kenneth D. West. 1987. A simple, positive semi-definite, heteroscedasticity and autocorrelation consistent covariance matrix. Econometrica 55: 703-8. [CrossRef]

Nguyen, Phong, and Wei-Han Liu. 2017. Time-varying linkage of possible safe haven assets: A cross-market and cross-asset analysis. International Review of Finance 17: 43-76. [CrossRef]

Pesaran, Hashem M., and Allan Timmermann. 1992. A simple nonparametric test of predictive performance. Journal of Business E Economic Statistics 10: 561-565.

Petty, William. 1690. Political Arithmetick. McMaster University Archive for the History of Economic Thought. Available online: https://ideas.repec.org/b/hay/hetboo/petty1690.html (accessed on 25 February 2020). 
Phillips, Peter, and Shu-Ping Shi. 2018. Financial bubble implosion and reverse regression. Econometric Theory 34: 705-53. [CrossRef]

Poshakwale, Sunil S., and Anandadeep Mandal. 2016. Determinants of asymmetric return co-movements of gold and other financial assets. International Review of Financial Analysis 47: 229-42. [CrossRef]

Ranaldo, Angelo, and Paul Söderlind. 2010. Safe haven currencies. Review of Finance 14: 385-407. [CrossRef]

Reboredo, Juan C. 2013. Is gold a hedge or safe haven against oil price movements? Resources Policy 38: 130-37. [CrossRef]

Syllignakis, Manolis N., and Georgios P. Kouretas. 2011. Dynamic correlation analysis of financial contagion: Evidence from the Central and Eastern European Markets. International Review of Economics and Finance 20: 717-32. [CrossRef]

Tamakoshi, Go, and Shigeyuki Hamori. 2014. Co-movements among major European exchange rates: A multivariate time-varying asymmetric approach. International Review of Economics and Finance 31: 105-13. [CrossRef]

Zeng, Fanhua, Wei-Chiao Huang, and James Hueng. 2016. On Chinese government's stock market rescue efforts in 2015. Modern Economy 7: 411-18. [CrossRef]

(C) 2020 by the author. Licensee MDPI, Basel, Switzerland. This article is an open access article distributed under the terms and conditions of the Creative Commons Attribution (CC BY) license (http://creativecommons.org/licenses/by/4.0/). 